\title{
What is it that we really do?
}

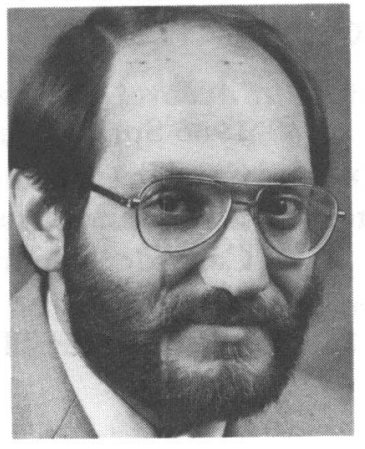

W ho of us in materials research has not encountered that question? It is a frequent one, usually posed by family and friends without technical backgrounds. To respond in a credible and informative way, most of us find considerable effort is needed. We need to draw not only on our talents as scientific researchers, but also on pedagogical talents which, for some of us, have not been well exercised. For the popular audience, we must not only start with a crystal clear understanding of what it is we want to say, but we must also employ concepts accessible to the layperson and terminology devoid of jargon to express ourselves. Whether chemist, metallurgist, physicist or biologist, the challenge is the same, and I for one have acquired a great deal of respect and admiration for those among us who do this well.

But wouldn't you think it would be easy to formulate the definition of what we as practitioners of basic and applied science do for an audience of our fellow scientists? In general the answer is yes. But in materials research it is apparently not that simple. This unique difficulty arose recently as part of the deliberative process that the MRS Publications Committee and Executive Council have devoted to the question of a Society-sponsored archival journal for materials research. In attempting to delineate possible definitions of scope and content of such a journal, several impediments became quite clear. First, it seems that individuals who do "materials research" disagree more as to its definition than do the same individuals when defining their own disciplinary field. Second, the highly successful MRS topical symposia and associated proceedings series serve only to define a segment of materials research and do that only by virtue of their existence. Thus this definition changes each year as the topical emphasis shifts. And third, we are faced with a two-dimensional parameter space in which to find our definition.

Praveen Chaudhari, in his recent editorial (MRS BULLETIN Vol. IX, No. 5, p. 28) pointed out that materials research today straddles the blurred boundary between science and technology. Where do we place the limit on the fundamental end of the spectrum between materials science and, say, condensed matter physics?

\section{It seems that individuals who do "materials research" disagree more as to its definition than they do when defining their own disciplinary field.}

\author{
Elton N. Kaufmann \\ MRS President
}

Similarily, where does the applied limit fall in the regions of process development and device fabrication? The second dimension is of course that of discipline. Whereas one can imagine a given materials study moving with the time along the science-technology dimension (perhaps not always with constant direction), the discipline dimension provides a breadth to the study encompassing fields as diverse as necessary to accomplish the job. While trying to construct a succinct and concise statement of "what it is we really do," one comes to the the realization that such a description does not exist. Rather we have a situation where the task at hand defines the approach, determines the disciplinary mix, mandates a more basic or more applied methodology, and thereby circumscribes a specific task-dependent definiton of materials.

Does this mean that a materials researcher must be a true generalist? Grounded in disciplinary training or at least emphasis, he/she must be sufficiently knowledgeable in both basic and applied aspects of a variety of disciplines to pursue a complete study. This may be the ideal, but it is hardly within a single person's ability to achieve. So just as in medicine, which Chaudhari points to as analogous to materials research, we retain our identification with certain specialties while trying to know enough about allied areas to guide a study through the interdisciplinary maze. There you have the central purpose of the multitopic interdisciplinary meetings which the MRS sponsors. On the recommendation of the MRS Publications Committee, the Council has overwhelmingly voted to institute a Society-sponsored journal. It will serve the scientific community through archival articles in qualitatively the same way as our meetings do, by providing in one place the two-dimensional coverage of this uniquely undefinable thing we do called "materials research." $\mathbf{M}|\mathbf{R}| \mathbf{S}$

The BULLETIN welcomes your response or opinion on this subject and others in the issue. 